Case Report

\title{
Meningothelial Meningioma Component in a Prepubertal Testicular Teratoma
}

\author{
Ruchi Sinha, ${ }^{1}$ Madhu Kumari $\mathbb{D}^{2},{ }^{2}$ Ranwir Kumar Sinha, ${ }^{2}$ and Bindey Kumar ${ }^{3}$ \\ ${ }^{1}$ Department of Pathology, AIIMS, Patna, India \\ ${ }^{2}$ Department of Pathology, AIIMS, Patna, India \\ ${ }^{3}$ Department of Paediatric Surgery, AIIMS, Patna, India
}

Correspondence should be addressed to Madhu Kumari; madhukumari372@gmail.com

Received 30 October 2019; Revised 29 December 2019; Accepted 7 January 2020; Published 21 January 2020

Academic Editor: Piero Tosi

Copyright (c) 2020 Ruchi Sinha et al. This is an open access article distributed under the Creative Commons Attribution License, which permits unrestricted use, distribution, and reproduction in any medium, provided the original work is properly cited.

Teratomas are nonseminomatous germ cell tumors composed of elements derived from more than one germinal layers (endoderm, mesoderm, and ectoderm). Malignant transformation of teratoma in the testis is well known; however, benign somatic neoplasm arising in a testicular teratoma is a rare occurrence. We report a case of meningothelial variant of meningioma arising in a pure and mature teratoma of the testis in a 5-year-old boy. Immunohistochemistry was positive for epithelial membrane antigen and vimentin. To our knowledge, this is the first report of meningothelial meningioma in a prepubertal testicular teratoma.

\section{Introduction}

Teratomas are tumors of germ cell origin with elements derived from more than one embryonic layer. They belong to the nonseminomatous germ cell tumor group. Teratomas can be classified as mature or immature depending upon the microscopic presence of well-differentiated tissue or immature fetal-like tissue, respectively [1]. The 2016 World Health Organization (WHO) classification differentiates testicular teratoma into prepubertal type and postpubertal type. It does not distinguish the postpubertal teratoma of the testis into mature and immature subtypes [2]. Here, we report a rare case of meningothelial variant of meningioma arising in a pure and mature testicular teratoma.

\section{Case Report}

A 5-year-old male patient presented with complaint of the left-sided testicular enlargement. On clinical examination, nontender testicular swelling was palpable. Ultrasonography showed a solid-cystic mass with multiple internal septations. On colour Doppler, the lesion appeared hypovascular. No extratesticular extension was observed. The right testis was of normal size and echotexture. Bilateral spermatic cords were normal. No metastatic foci or lymphadenopathy was detectable. Chest radiograph was normal. Serum testicular tumour markers were within normal range. A left orchiectomy was performed and sent for histopathology.

Grossly, the left orchiectomy specimen measured $3.4 \times 1.5 \times 1 \mathrm{~cm}$. On cut section, a solid-cystic area measuring $1.4 \times 0.5 \mathrm{~cm}$ was seen within the testis. Tissue was focally hard. The lesion was located entirely within the confines of the testis.

On microscopic examination, multiple sections from the left testicular swelling showed a tumour composed of mature tissue derived from all the three germ layers-mature cartilage tissue, cystic spaces lined respiratory epithelium, glial tissue, adipose tissue, and muscle (Figure 1). In the solid area, admixed with the other teratomatous components, meningioma-like areas were identified which showed whorled arrangement of cells. These cells had oval nucleus, eosinophilic cytoplasm, and indistinct cell borders. Few psammoma bodies were also seen (Figures 2 and 3). This meningothelial component accounted for a major portion (more than 10\%) of the entire teratomatous tissue and was present in all the five slides that contained teratoma. Morphologically, the pattern of growth resembled meningioma (whorled growth pattern) than meningothelial proliferation. 


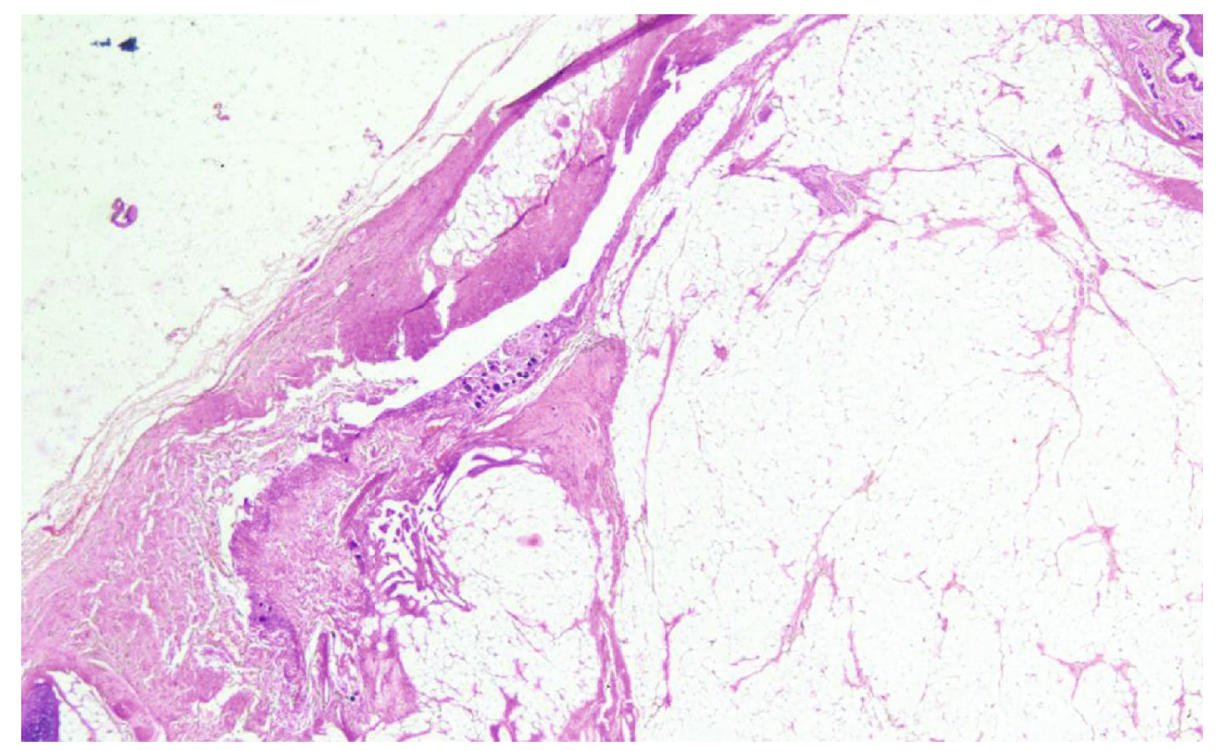

Figure 1: Tumour composed of mature tissues derived from different germinal layers (H\&E; 4x).

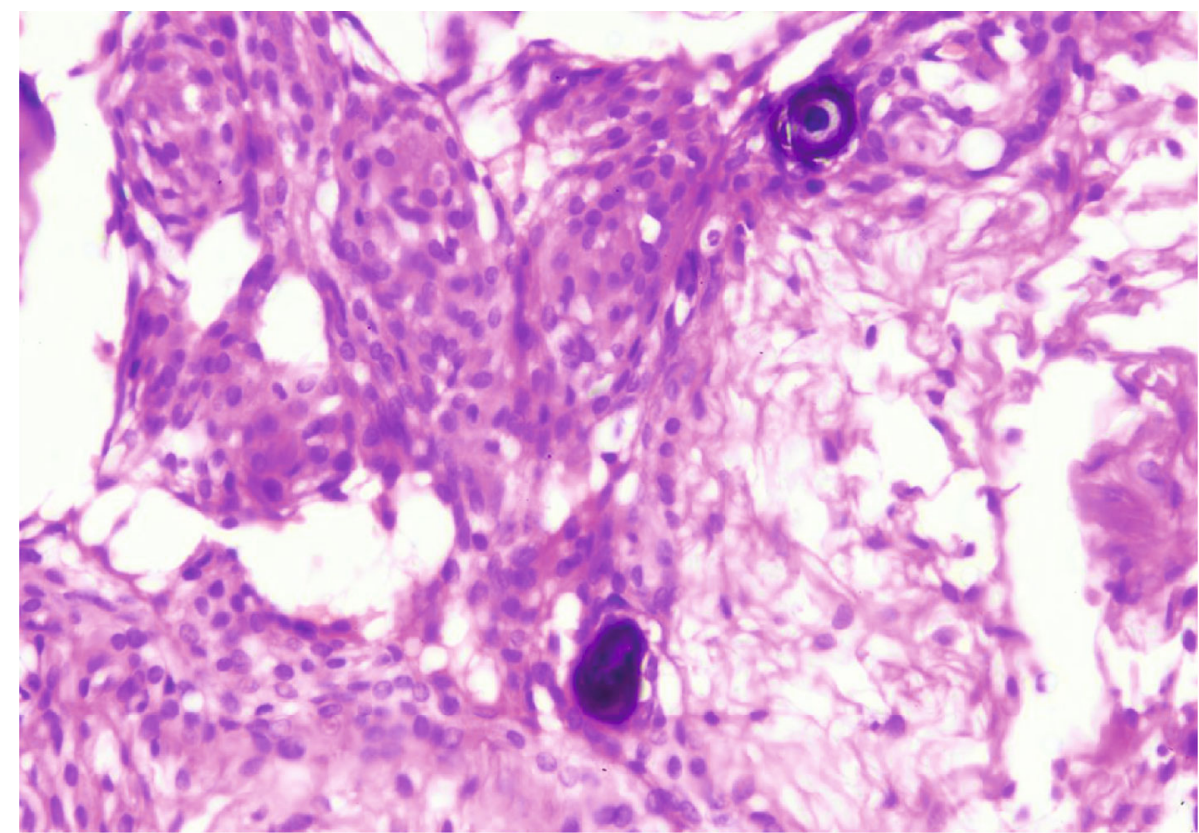

FIGURE 2: Whorled arrangement of meningothelial cells with the presence of psammoma bodies (H\&E; 10x).

No component of germ cell neoplasm in situ (GCNIS) was found. No microscopic evidence of extratesticular extension or lymphovascular invasion was found.

On immunohistochemistry (IHC), the meningiomatous component showed diffuse strong vimentin and epithelial membrane antigen (EMA) positivity (Figures 4 and 5).

\section{Discussion}

Teratomas are germ cell tumours (GCT). They can be gonadal or extragonadal in location. It is the second most common paediatric GCT of the testis [3]. They account for
$5 \%$ to $10 \%$ of all testicular neoplasms [4]. It can present as an insidiously growing testicular mass or as a painful lesion if associated with hemorrhage [5].

The 2016 WHO classification differentiates testicular teratoma into prepubertal type and postpubertal type. It does not distinguish mature from immature teratoma of the postpubertal testis [2]. Prepubertal teratomas show organoid architecture with minimal cytological atypia [6], are not associated with GCNIS [7], usually lack $12 p$ abnormality [8], and rarely metastasize [9].

Teratoma comprises of different types of tissues arising from two or more germinal layers. Thus, a variety of 


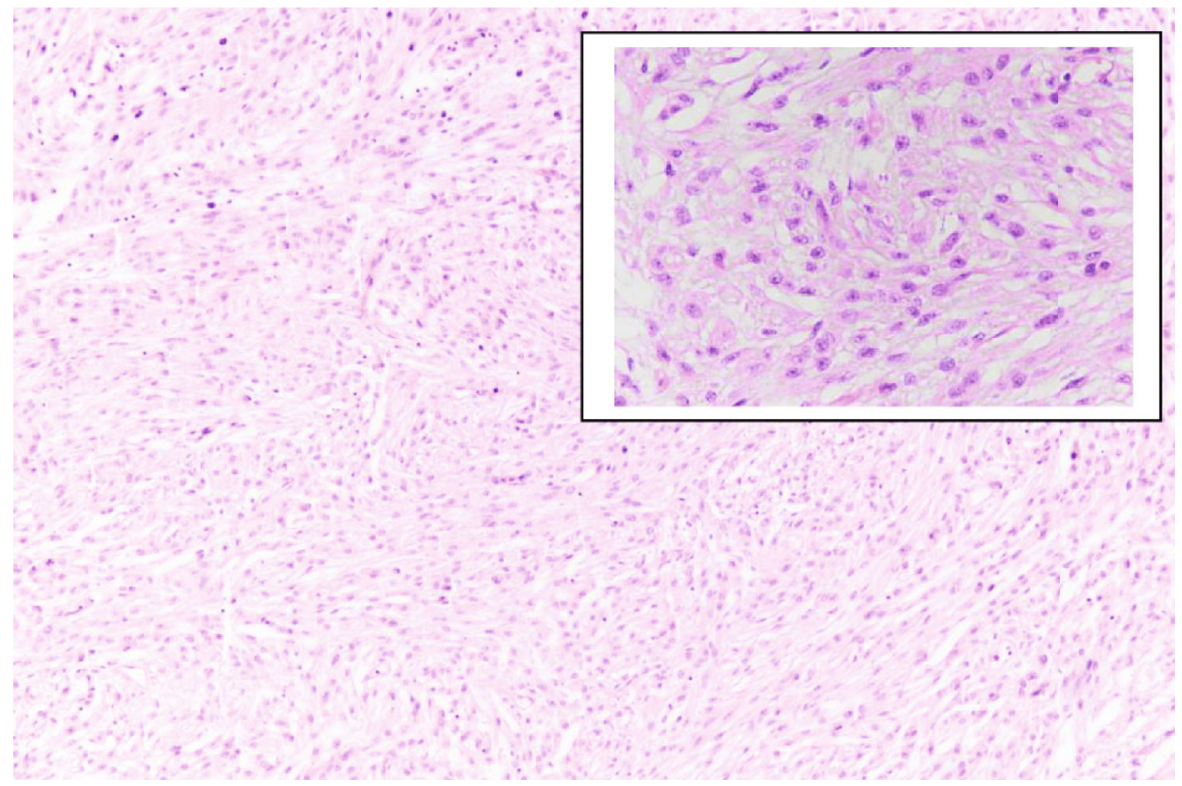

FIGURE 3: Meningothelial meningioma component with whorls of meningothelial cells (H\&E; 10x. Inset: H\&E; 40x).

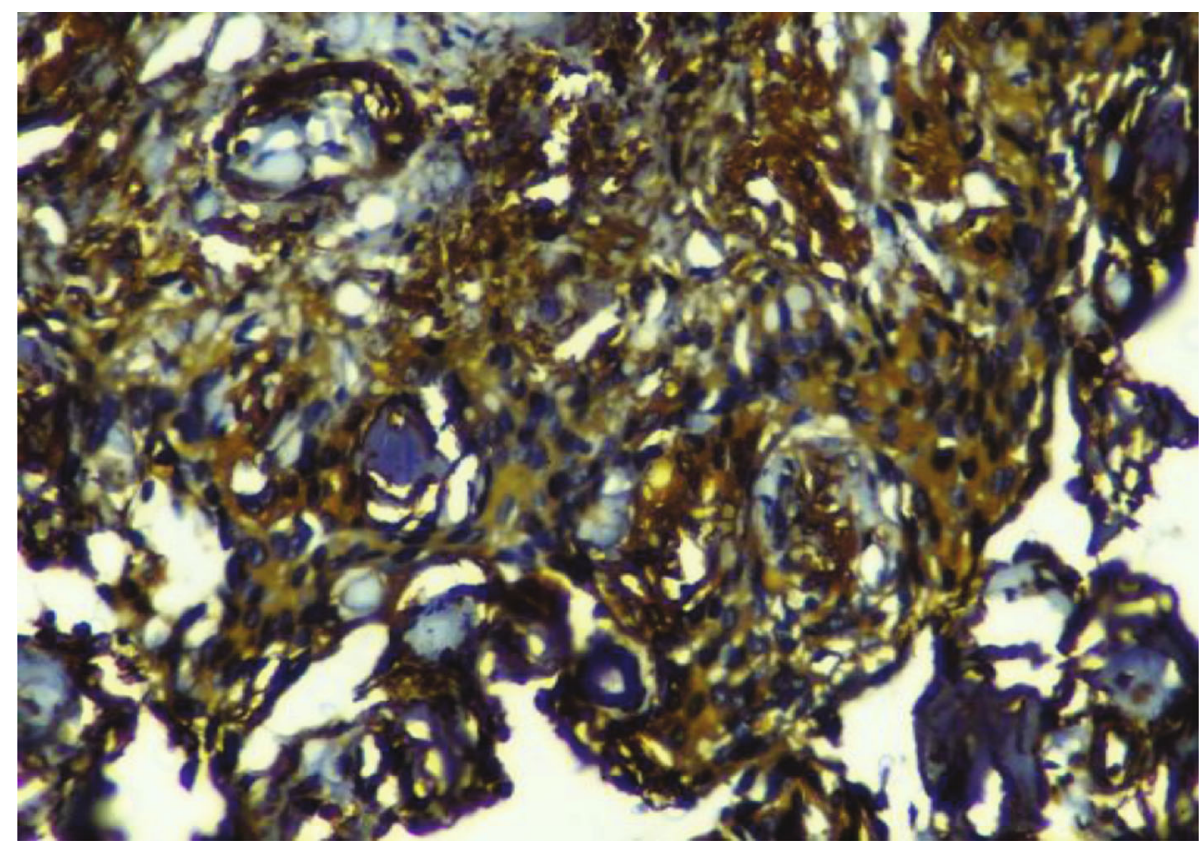

FIGURE 4: Meningothelial cells showing strong and diffuse positivity for vimentin (IHC; 40x).

secondary somatic, both benign and malignant, neoplasms can arise from any of the three germ cell layers of a teratoma. Secondary somatic neoplasms are thought to arise due to overgrowth of a particular component of the teratoma [10]. Malignant neoplasms are more commonly encountered as compared to benign tumours. The most common somatic malignancy arising in teratoma of testis is sarcoma [11]. Identifying the biological nature and extent of spread of the secondary nongerm cell somatic-type neoplasm has prognostic significance $[4,12]$. Patients in whom malignant component is localized to the testis hav- ing better prognosis than those in whom the malignant component metastasizes [13].

Reports of secondary benign somatic tumors arising in teratomas are very rare. They are more commonly encountered in the ovary as compared to the testis [4]. Secondary benign nongerm cell-type tumor in testicular teratoma is infrequent.

Ectodermal-derived benign tumours arising in testicular teratoma are extremely rare. On extensive search of English literature, only two cases of meningioma have been reported. One case was of a microcystic variant of meningioma which 


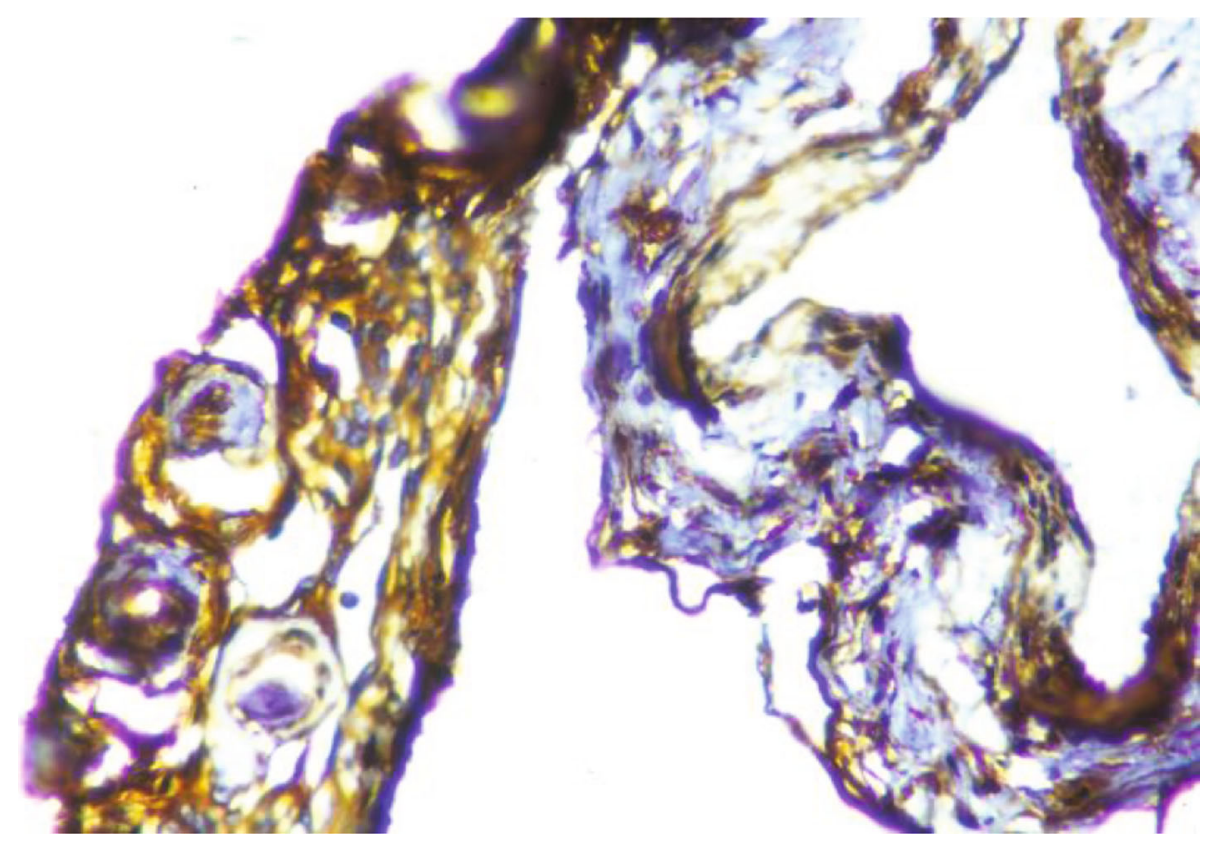

FIgURE 5: Positive staining for epithelial membrane antigen in meningothelial cells (IHC; 40x).

developed in mixed germ cell testicular teratoma in a 29 year-old man [4] and second case report is of a psammomatous variant arising in a pure testicular teratoma in a 46-yearold male [12].

Meningothelial proliferations containing psammoma bodies have been reported in mature testicular teratoma $[14,15]$. Meningothelial proliferations are seen microscopically as interanastomosing slit-like channels lined by spindle or cuboidal cells within a dense fibrocollagenous stroma. These are mostly seen in peripheral parts of the teratoma and in close proximity of peripheral nerve bundles, glial tissue, and skin with abundant pilosebaceous unit. Scattered pigment cells and psammomatous concretions can be present. Whorled nests of meningothelial cells are rarely found in meningothelial proliferations [16]. To label such a proliferation as meningioma, it should constitute a major component of the teratoma, as in the present case (more than 10\%). Allen et al. in their case report of microcystic meningioma had meningomatous component accounting for approxmitaley $15 \%$ of the teratomatous tissue [4]. Outgrowth of the meningothelial elements in the presence of psammoma bodies indicates the presence of benign meningioma within a teratoma [17]

Our case has two interesting features; it is not only the first case of meningioma arising in a pure prepubertal testicular teratoma in a 5-year-old boy but is also the first case of meningothelial variant. This is an extremely rare occurrence in a testicular teratoma and adds to the medical literature a unique case of benign tumor originating in a prepubertal testicular teratoma.

\section{Conflicts of Interest}

The authors declare that they have no conflicts of interest.

\section{References}

[1] F. K. Mostofi I. A. Sesterhenn et al., Pathology and Genetics of Tumours of the Urinary System and Male Genital Organs, J. N. Elbe, G. Sauter, J. I. Epstein, and I. A. Sesterhenn, Eds., IARC Press, Lyon, 2004.

[2] T. M. Ulbright, M. B. Amin, B. Balzer et al., "Germ cell tumours," in World Health Organization Classification of Tumours of the Urinary System and Male Genital Organs, $\mathrm{H}$. Moch, P. A. Humphreyu, T. M. Ulbright, and V. E. Reuter, Eds., pp. 189-226, IARC Press, Lyon, 2016.

[3] S. A. Brosman, "Testicular tumors in prepubertal children," Urology, vol. 13, no. 6, pp. 581-588, 1979.

[4] E. A. Allen, P. C. Burger, and J. I. Epstein, "Microcystic meningioma arising in a mixed germ cell tumor of the testis: a case report," The American Journal of Surgical Pathology, vol. 23, no. 9, pp. 1131-1135, 1999.

[5] D. Wetherell, M. Weerakoon, D. Williams et al., "Mature and immature teratoma: a review of pathological characteristics and treatment options," Medical \& Surgical Urology, vol. 3, no. 1, 2014.

[6] C. Zhang, D. M. Berney, M. S. Hirsch, L. Cheng, and T. M. Ulbright, "Evidence supporting the existence of benign teratomas of the postpubertal testis: a clinical, histopathologic, and molecular genetic analysis of 25 cases," The American Journal of Surgical Pathology, vol. 37, no. 6, pp. 827-835, 2013.

[7] T. M. Ulbright and J. R. Srigley, "Dermoid cyst of the testis: a study of five postpubertal cases, including a pilomatrixomalike variant, with evidence supporting its separate classification from mature testicular teratoma," The American Journal of Surgical Pathology, vol. 25, no. 6, pp. 788793, 2001.

[8] K. M. Cornejo, L. Cheng, A. Church, M. Wang, and Z. Jiang, "Chromosome 12p abnormalities and IMP3 expression in prepubertal pure testicular teratomas," Human Pathology, vol. 49, pp. 54-60, 2016. 
[9] R. W. Grady, J. H. Ross, and R. Kay, "Epidemiological features of testicular teratoma in a prepubertal population," The Journal of Urology, vol. 158, 3 Part 2, pp. 1191-1192, 1997.

[10] J. B. Kum, T. M. Ulbright, S. R. Williamson et al., "Molecular genetic evidence supporting the origin of somatic-type malignancy and teratoma from the same progenitor cell," The American Journal of Surgical Pathology, vol. 36, no. 12, pp. 1849-1856, 2012.

[11] T. M. Ulbright, P. J. Loehrer, L. M. Roth, L. H. Einhorn, S. D. Williams, and S. A. Clark, "The development of non-germ cell malignancies within germ cell tumors. A clinicopathologic study of 11 cases," Cancer, vol. 54, no. 9, pp. 1824-1833, 1984.

[12] F. M. Castro Pereira, M. G. de Oliveira, L. C. Almeida, B. C. Pires, and J. de Bessa Júnior, "A rare component of psammomatous meningioma in a testicular teratoma," Case Reports in Pathology, vol. 2013, Article ID 645415, 3 pages, 2013.

[13] T. Ahmed, G. J. Bosl, and S. I. Hajdu, "Teratoma with malignant transformation in germ cell tumors in men," Cancer, vol. 56, no. 4, pp. 860-863, 1985.

[14] M. Michal, "Meningeal nodules in teratoma of the testis," Vircows Archiv, vol. 438, no. 2, pp. 198-200, 2001.

[15] K. V. Shelekhova, D. V. Kazakov, and M. Michal, "Testicular teratoma with meningothelial elements," Arkhiv Patologii, vol. 67, no. 5, pp. 37-38, 2005.

[16] E. Chen, C. D. M. Fletcher, and M. R. Nucci, "Meningothelial proliferations in mature cystic teratoma of the ovary: evidence for the common presence of cranially derived tissues paralleling anterior embryonic plate development. An analysis of 25 consecutive cases," The American Journal of Surgical Pathology, vol. 34, no. 7, pp. 1014-1018, 2010.

[17] S. Mandal, K. Dhingra, P. Gupta, and N. Khurana, "Rare growth of a psammomatous meningioma in a mature ovarian teratoma: a case report," Pathology, Research and Practice, vol. 206, no. 5, pp. 322-324, 2010. 


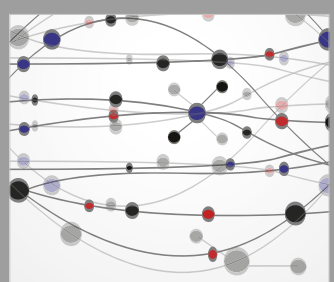

The Scientific World Journal
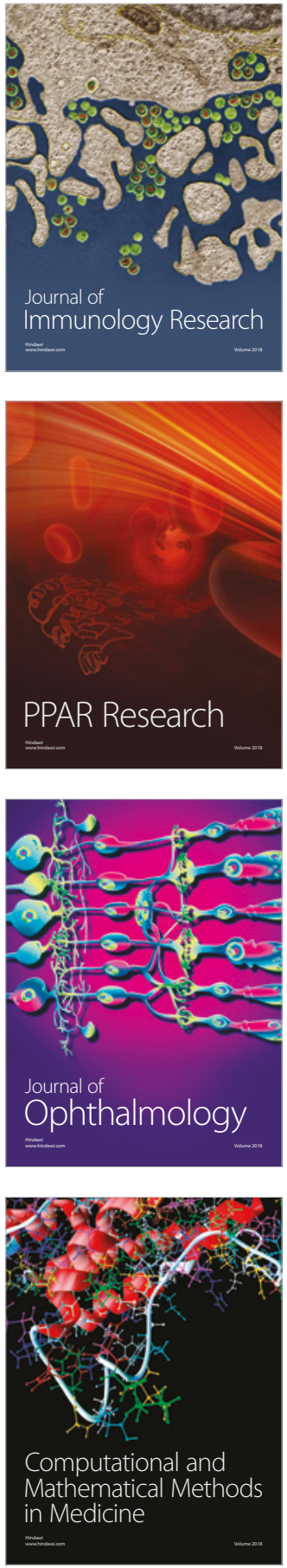

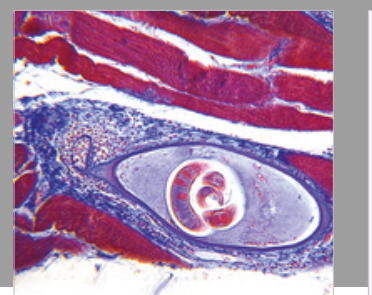

Gastroenterology Research and Practice

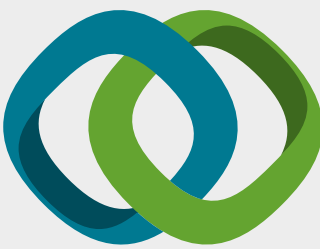

\section{Hindawi}

Submit your manuscripts at

www.hindawi.com
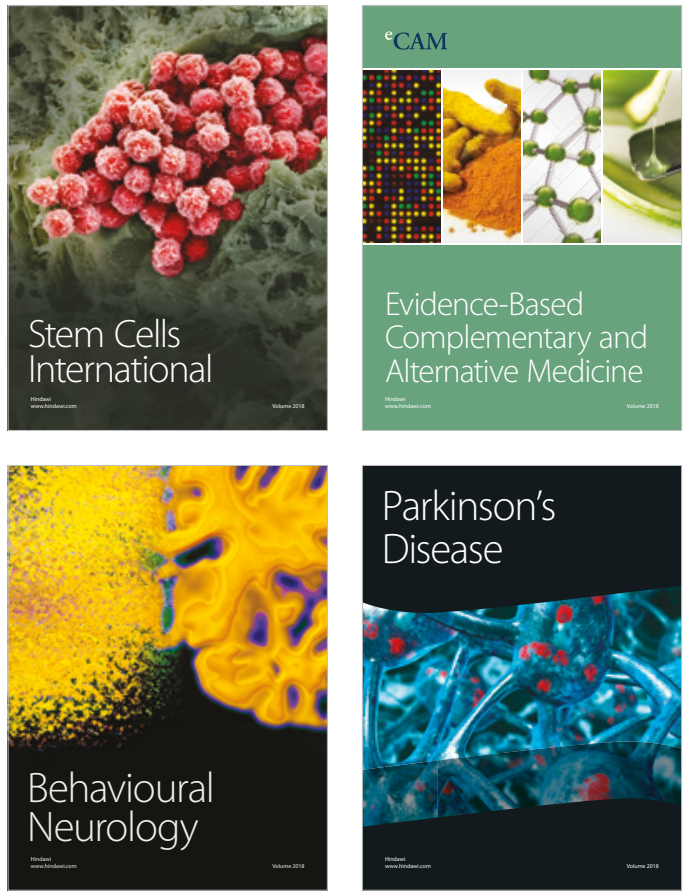

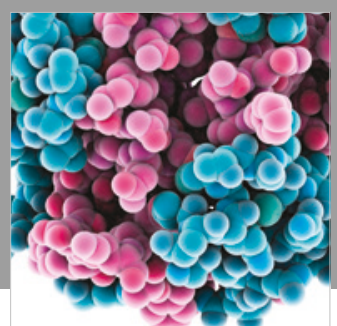

ournal of

Diabetes Research

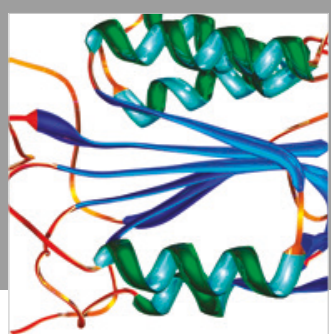

Disease Markers
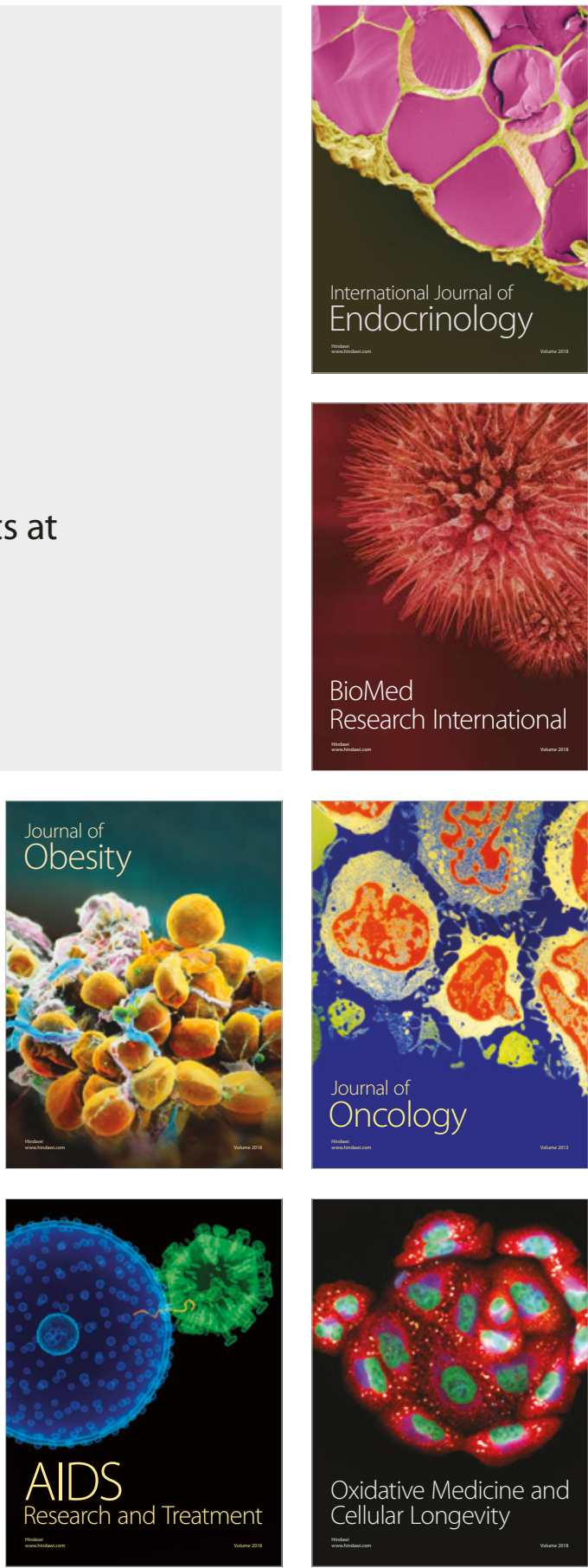